\begin{tabular}{|ll|}
\hline Received & $:$ 30 September 2019 \\
Revised & $:$ 1 Oktober 2019 \\
Accepted & $:$ 22 Oktober 2019 \\
Online & $:$ 25 Oktober 2019 \\
Published & $:$ 29 Oktober 2019
\end{tabular}

\title{
APLIKASI BELAJAR ONLINE BERBASIS WEB SEBAGAI OPTIMALISASI PEMBELAJARAN UNTUK SISWA SMK
}

\author{
Adi Rahman ${ }^{1)}$ \\ ${ }^{1}$ Fakultas Matematika dan Ilmu Pengetahuan Alam, Universitas Negeri Jakarta \\ email: adirahman47@gmail.com
}

\begin{abstract}
The spread of massive internet connectivity and penetration of smart devices is a supporting factor why the approach of educational technology is an appropriate step. Currently online learning applications themselves are used for the public both from the level, elementary, junior high, to high school that students get at school can be learned through this online learning application. Now the more widespread online learning applications in Indonesia and more and more people are taking the initiative in making online-based learning with more interesting and creative features. However, no one has specifically developed a specific online learning application for students in vocational high schools. Their existence seems to be marginalized due to the community paradigm which assumes that vocational school children do not need alternative tutoring apart from teachers at school. Though they also need the same thing with high school students and others. Based on this analysis, researchers wanted to create a web-based online learning application for vocational students. Achievement Jack is an online learning application based on learning management system that allows students to be able to do learning through videos delivered by tutors. This study uses the Software Development Life Cycle (SDLC) waterfall type method, or hereinafter referred to as the waterfall method. Based on the above calculation, from 3 testers who filled out the questionnaire stated that this learning application was running with the results of testing the user interface 98\%, the basic functions of the system 100\%, and 100\% validation. In conclusion, this application runs very well.
\end{abstract}

Keywords: Application, Learning, Online, Vocational School.

\begin{abstract}
Abstrak
Penyebaran konektivitas internet besar-besaran dan penetrasi perangkat pintar adalah faktor pendukung mengapa pendekatan teknologi pendidikan adalah langkah yang tepat. Saat ini aplikasi pembelajaran online sendiri digunakan untuk umum baik dari level, SD, SMP, hingga SMA yang siswa dapatkan di sekolah dapat dipelajari melalui aplikasi pembelajaran online ini. Sekarang semakin banyak aplikasi pembelajaran online di Indonesia dan semakin banyak orang mengambil inisiatif dalam membuat pembelajaran berbasis online dengan fitur yang lebih menarik dan kreatif. Namun, tidak ada yang secara khusus mengembangkan aplikasi pembelajaran online khusus untuk siswa di sekolah menengah kejuruan. Keberadaan mereka tampaknya terpinggirkan karena paradigma masyarakat yang menganggap bahwa anak-anak sekolah kejuruan tidak perlu bimbingan belajar selain dari guru di sekolah. Padahal mereka juga membutuhkan hal yang sama dengan siswa SMA dan lainnya. Berdasarkan analisis ini, peneliti ingin membuat aplikasi pembelajaran online berbasis web untuk siswa kejuruan. Achievement Jack adalah aplikasi pembelajaran online berbasis sistem manajemen pembelajaran yang memungkinkan siswa untuk dapat belajar melalui video yang
\end{abstract}


disampaikan oleh tutor. Penelitian ini menggunakan metode tipe air terjun Life Development Cycle (SDLC), atau yang selanjutnya disebut metode air terjun. Berdasarkan perhitungan di atas, dari 3 penguji yang mengisi kuesioner menyatakan bahwa aplikasi pembelajaran ini berjalan dengan hasil pengujian antarmuka pengguna $98 \%$, fungsi dasar sistem $100 \%$, dan validasi $100 \%$. Kesimpulannya, aplikasi ini berjalan dengan sangat baik.

Kata kunci: Aplikasi, Pembelajaran, Online, Sekolah Kejuruan.

\section{PENDAHULUAN}

Pendidikan sekarang ini mengalami peningkatan yang cukup signifikan antara lain pada sistem, metode, maupun media pembelajaran yang digunakan. Seiring dengan berkembangnya teknologi saat ini, muncul permasalahan dalam hal pemanfaatannya. Teknologi yang ada saat ini sudah semakin canggih, akan tetapi tidak diimbangi dengan kemampuan pemahaman dari masyarakat (Chusna, 2017). Salah satu area teknologi informasi yang dapat dijadikan solusi terhadap permasalahan yang dihadapi masyarakat yaitu berada disektor pendidikan.

Di negara dengan penduduk yang banyak seperti Indonesia, pendidikan merupakan sebuah pasar yang cukup menjanjikan. Pada tahun ajaran 2016/2017 yang lalu, ada sekitar dua ratus ribu sekolah dari jenjang Sekolah Dasar (SD) hingga Sekolah menengah Atas (SMA) yang beroperasi di tanah air (Nugrahanto, 2018). Sekolah-sekolah tersebut pun mempunyai total siswa yang sangat banyak, mencapai 45 juta orang. Angka tersebut bahkan belum ditambah murid Sekolah Menengah Kejuruan (SMK) sebanyak 4,8 juta orang.

Dari total jumlah siswa SMK yang tersebar di seluruh Indonesia, terdapat permasalahan yang cukup penting yaitu tingkat pengangguran pada lulusan Sekolah Menengah Kejuruan (SMK) tercatat paling tinggi di antara lulusan dari jenjang pendidikan lainnya. Lulusan sekolah menengah kejuaran (SMK) menjadi penyumbang tertinggi pengangguran terbuka di Indonesia, bertolak belakang dengan rencana awal menjadikan lulusan SMK langsung bisa diserap oleh dunia usaha. Badan Pusat Statistik (BPS) mencatat, dari 7 juta pengangguran terbuka per Agustus 2018, 11,24 persennya merupakan lulusan SMK. Persentase itu lebih tinggi dari pengangguran terbuka lulusan SMA 7,95 persen, lulusan SD 2,43 persen, sedangkan untuk lulusan SMP yang menganggur ada sebanyak 4,8 persen.

Salah seorang Ekonom, Raden Pardede mengatakan bahwa angka pengangguran yang tinggi pada lulusan SMK membuktikan kualitas SMK rendah. Sampai saat ini komposisi tenaga kerja Indonesia lebih didominasi lulusan Sekolah Menengah Atas (SMA) ke bawah. Akibatnya, daya saing Indonesia dibanding negara-negara lain rendah. Dia mengingatkan, pemerintah harus mengontrol dan membangun pendidikan vokasi yang berkualitas untuk Sekolah Menengah Kejuruan (SMK).

Menteri Pendidikan dan Kebudayaan (Mendikbud) Muhadjir Effendy memaparkan penyebabnya dari mulai daya serap industri yang tidak seimbang dengan jumlah lulusan SMK, hingga guru yang tidak menguasai bidang ajarannya. Selain itu, keterbatasan guru juga jadi masalah untuk pengembangan lulusan SMK. Jumlah guru bidang yang dibutuhkan mencapai 91 ribu orang. Namun, Lembaga Pendidikan Tenaga Kepen didikan (LPTK) tidak mencetak calon guru sesuai bidang, seperti pertanian, kelautan, atau industri kreatif. Guru yang dicetak dari LPTK hanya mengusasi ilmu murni.

Salah satu upaya yang dapat dilakukan untuk mengurangi pengangguran terbuka pada lulusan SMK adalag dengan meningkatkan kualitas pendidikan. Kualitas pendidikan dapat ditingkatkan melalui pengembangan proses pembelajaran. Dengan demikian, maka peningkatan kualitas proses pembelajaran tersebut otomatis akan berpengaruh pada peningkatan lulusan sekolah (Jamaluddin, 2011). Pengembangan kualitas proses pembelajaran ini tergantung pada manajemen sekolah serta pendekatan pendekatan pembelajaran para guru.

Dengan persebaran konektivitas internet yang masif serta penetrasi perangkat pintar, pendekatan teknologi pada bidang pendidikan merupakan sebuah langkah yang tepat (Mulyadi, 2010). Berkembangannya aplikasi belajar online dewasa ini sangat membantu siswa dalam memahami pelajaran yang diberikan di sekolah . Saat ini aplikasi belajar online sendiri dipergunakan untuk 
umum baik dari tingkat, SD, SMP, SMA hingga Universitas. Pelajaran yang siswa dapatkan di sekolah dapat dipelajari lewat aplikasi belajar online ini. Kurikulum yang disiapkan pemerintah juga diadopsi ke dalam aplikasi belajar online. Kini semakin maraknya aplikasi belajar online di Indonesia dan kian banyak orang-orang yang berinisiatif dalam membuat pembelajaran berbasis online dengan fitur yang lebih menarik dan kreatif. Beberapa aplikasi belajar online terkenal di Indonesia seperti Zenius dan Ruang Guru hadir sebagai bentuk revolusi pendidikan di Indonesia yang terintegrasi terhadap semua pelajar di Indonesia.

Aplikasi adalah penggunaan dalam suatu komputer, instruksi atau pernyataan yang disusun sedemikian rupa sehingga komputer dapat memproses input menjadi output (Pressman, 2002). Menurut kamus besar bahasa indonesia (1998) "Aplikasi adalah penerapan dari rancang sistem untuk mengolah data yang menggunakan aturan atau ketentuan bahasa pemrograman tertentu". Aplikasi adalah suatu program komputer yang dibuat untuk mengerjakan dan melaksanakan tugas khusus dari pengguna. Aplikasi merupakan rangkaian kegiatan atau perintah untuk dieksekusi oleh komputer. Program merupakan kumpulan instructionset yang akan dijalankan oleh pemroses, yaitu berupa software.

Gregorius (2000) mengatakan bahwa website adalah kumpulan halaman web yang saling terhubung dan file-filenya saling terkait. Web terdiri dari page atau halaman, dan kumpulan halaman yang dinamakan home page. Home page berada pada posisi teratas, dengan halaman-halaman terkait berada di bawahnya. Biasanya setiap halaman di bawah home page disebut child page, yang berisi hyperlink ke halaman lain dalam web.

Arief (2011) mengungkapkan bahwa website adalah salah satu aplikasi yang berisikan dokumendokumen multimedia (teks, gambar, animasi, video) didalamnya yang menggunakan protokol HTTP (Hypertext Transfer Protocol) dan untuk mengaksesnya menggunakan perangkat lunak yang disebut browser.

Sebuah website biasanya bisa diakses secara umum. Kebanyakan website dapat diakses melalui public internet protocol (IP) dalam sebuah jaringan internet. Namun tidak menutup kemungkinan bahwa website tersebut diakses secara offline melalui jaringan LAN.

Website bisa berupa website pribadi, komersial, pemerintahan, dan website lainnya yang dibuat untuk kepentingan profit maupun non profit yang dipublikasikan secara umum. Selain itu, website juga dapat dibuat untuk tujuan khusus seperti misalnya untuk hiburan, pendidikan, dan juga kepentingan sosial. 


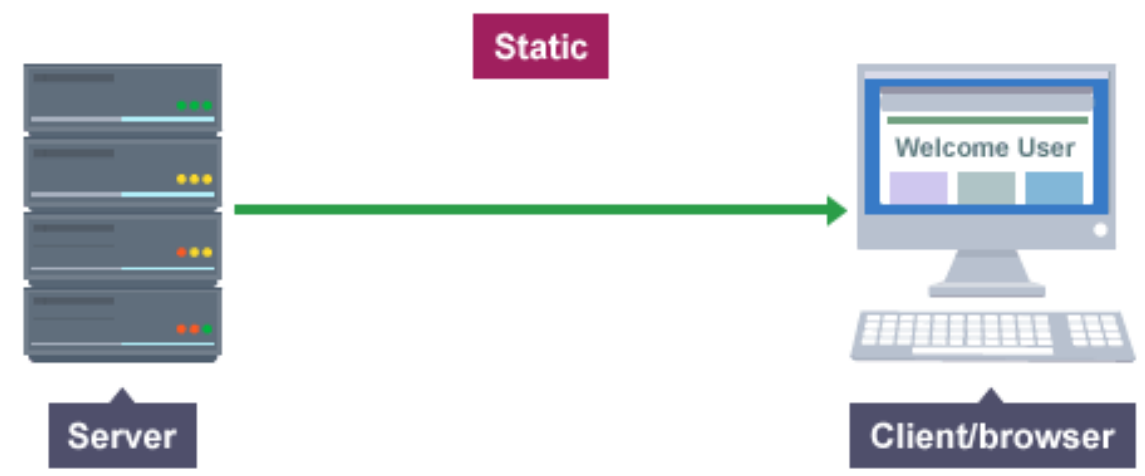

\section{Dynamic}
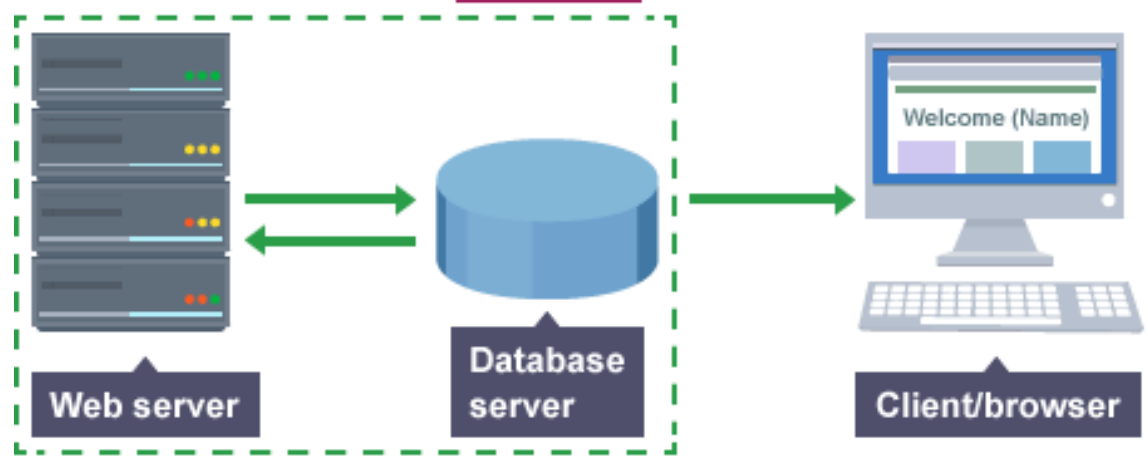

Gambar 1. Website Static dan Website Dynamic

(Sumber: springworkz.biz)

Berdasarkan penampilan dan respon ketika diakses, website bisa dikategorikan ke dalam dua jenis utama yaitu static website dan dynamic website. Static website pada umumnya merupakan informasi yang disimpan di dalam server dengan format tertentu yang nantinya akan tampil secara identik untuk semua pengguna atau users. Website jenis ini umumnya dikembangkan dengan menggunakan Bahasa pemrograman Hypertext Markup Language (HTML) ataupun Cascading Style Sheets (CSS).

Berbeda dengan static website, dynamic website mempunyai kemampuan untuk menyesuaikan dirinya sesuai dengan keadaan saat users mengakses website tersebut dengan memanfaatkan database.

XAMPP merupakan perangkat lunak yang dikembangkan dari LAMP yang terdiri dari beberapa perangkat lunak seperti (Linux, Apache, MySQL, PHP, dan PERL) sebagai project non profit yang dikembangkan oleh Apache Friends. Apache Friends sendiri terdiri dari Tim Inti (Core Team), Tim Pengembang (Development Team) dan Tim Dukungan (Support Tim) yang didirikan Kai Oswalad Seidler dan Kay Vogelgesang pada tahun 2002. Project ini berguna untuk mempromosikan penggunaan Apache web browser. 


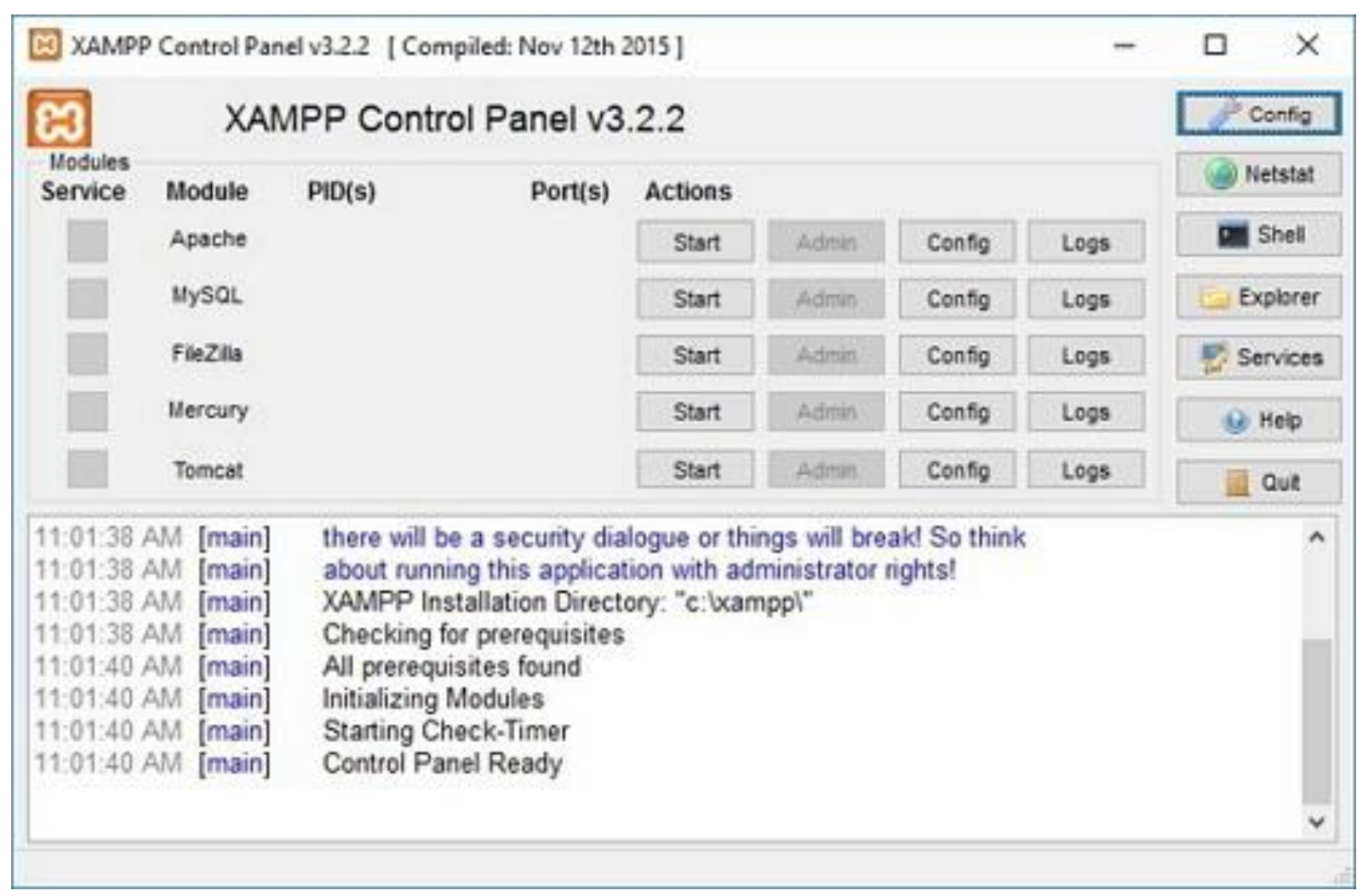

Gambar 2. Tampilan XAMPP

(Sumber: global-komputer.com )

Riyanto (2010) mengemukakan bahwa XAMPP adalah seperangkat paket PHP dan MySQL yang memiliki basis open source, dimana software ini dapat digunakan sebagai alat pembantu untuk mengembangkan aplikasi berbasis PHP. XAMPP ini berupa satu paket aplikasi yang berisi beberapa perangkat lunak yang berbeda-beda.

Wicksono (2008) menjelaskan bahwa XAMPP adalah sebuah software yang memiliki tugas untuk menjalankan website berbasis PHP dengan menggunakan pengolah data berupa MySQL pada komputer lokal. XAMPP ini juga dikenal sebagai Cpanel server yang mampu melakukan preview website tanpa harus tersambung dengan jaringan internet ataupun online.

Dari kedua pengertian menurut para ahli diatas mengenai XAMPP dapat diambil kesimpulan bahwa XAMPP merupakan sebuah paket perangkat lunak (Linux, Apache, MySQL, PHP, dan Perl) yang berisi platform perangkat lunak yang berbeda-beda dengan platform gratis serta open source yang dikembangkan oleh perusahaan Apache Friends.

XAMPP bisa dijalankan di 4 platform OS, yaitu Windows, Linux, Mac OS dan Solaris. Pada XAMPP terdapat Apache yang merupakan aplikasi web server yang bersifat open source. Open source artinya dapat diperoleh secara gratis dan dikembangkan oleh setiap orang. Fungsi XAMPP sendiri adalah sebagai server yang berdiri sendiri (localhost), yang terdiri beberapa program antara lain: Apache HTTP Server, MySQL database dan penerjemah bahasa yang ditulis dengan bahasa pemrograman PHP dan Perl.

Namun demikian, belum ada yang khusus mengembangkan secara spesifik aplikasi belajar online untuk murid di SMK. Keberadaan mereka seakan-akan termarjinalkan akibat paradigma masyarakat yang menganggap bahwa anak SMK tidak membutuhkan bimbingan belajar alternatif selain dari guru di sekolah. Padahal mereka juga membutuhkan hal yang sama dengan murid SMA dan lainnya.

Saat ini hanya terdapat artikel-artikel tentang pelajaran dan video-video di youtube yang membahas mengenai pelajaran di SMK namun tidak terintegrasi dan terstruktur satu sama lainnya. 
Berdasarkan analisis tersebut, peneliti ingin membuat aplikasi belajar online berbasis web yang diberi nama Dongkrak Prestasi.

Dongkrak Prestasi merupakan aplikasi belajar online berbasis learning management system yang memungkinkan memungkinkan siswa dapat melakukan pembelajaran melalui video yang disampaikan oleh tutor. Dongkrakprestasi membantu siswa SMK untuk memahami materi kejuruan yang dipelajarinya di sekolah serta mempersiapkan diri menghadapi ujian semester. Selain itu, terdapat soal-soal latihan yang memudahkan siswa untuk mengerjakan latihan soal dari berbagai topik serta dilengkapi dengan sistem analisis dan gamifikasi sehingga proses latihan menjadi menjadi menarik dan memotivasi untuk mengasah kemampuan diri terus menerus. Kemudian siswa akan mendapatkan pengalaman belajar seru melalui ribuan video konsep dan pembahasan pelajaran sesuai pilihan jurusan siswa.

Dengan demikian adanya Dongkrakprestasi, murid tidak perlu lagi harus belajar melalui guru saat di sekolah saja karena mereka bisa belajar kapanpun mereka mau setiap membawa laptop atau smartphone dengan mengakses aplikasi belajar online. Dongkrak Prestasi hadir sebagai aplikasi belajar online yang dengan mudah diakses, beberapa fitur yang tersedia memungkinkan siswa SMK untuk mengasah kemampuannya sehingga dapat mencapai hasil yang diinginkan. Dengan adanya aplikasi belajar online untuk siswa SMK ini diharapkan mampu menjadi solusi untuk siswa SMK memahami pelajaran kejuruannya di sekolah.

\section{METODE PENELITIAN}

Penelitian ini menggunakan metodologi Software Development Life Cycle (SDLC) tipe waterfall atau selanjutnya disebut metode waterfall. Metode ini dipilih karena tahapannya yang sistematis dan mudah diaplikasikan. Adapun tahapan yang dilakukan terdiri dari analisis kebutuhan, desain sistem, implementasi, pengujian, dan pemeliharaan. Untuk tahap pemeliharaan tidak akan dibahas pada penilitian ini karena tahapan tersebut dilaksanakan untuk menjaga aplikasi untuk terus dikembangkan. Untuk pengumpulan data identifikasi masalah, peneliti menggunakan metode wawancara tidak terstruktur kepada beberapa narasumber yang mempunyai riwayat pendidikan pada jenjang SMK.

Pada penelitian ini, metode pengujian yang akan digunakan untuk mengembangkan aplikasi ini adalah blackbox testing. Blackbox testing atau bisa disebut tes fungsional ini adalah pengujian yang dilakukan hanya dengan mengamati hasil eksekusi melalui data uji dan memeriksa fungsional dari aplikasi yang sedang dikembangkan. Blackbox testing telah banyak diujikan pada pengembangan aplikasi, seperti pengembangan aplikasi augmented reality (Sumardani, 2019) dan pengembangan aplikasi web (Kurniawan, 2018).

Pengujian program aplikasi ini dilakaukan oleh pengembang dan user yang terlibat untuk memberi data yang akan di-input. Selain itu user mencoba berbagai fitur pada aplikasi ini. Ada beberapa tahapan pengujian yang akan dilakukan, antara lain pengujian interface, pengujian fungsi dasar sistem, pengujian validasi,dan real testing. 


\section{HASIL DAN PEMBAHASAN}

\section{Hasil Implementasi Antarmuka}

Pembuatan antarmuka dilakukan menggunakan HTML (Hypertext Markup Language), CSS (Cascading Style Sheet).

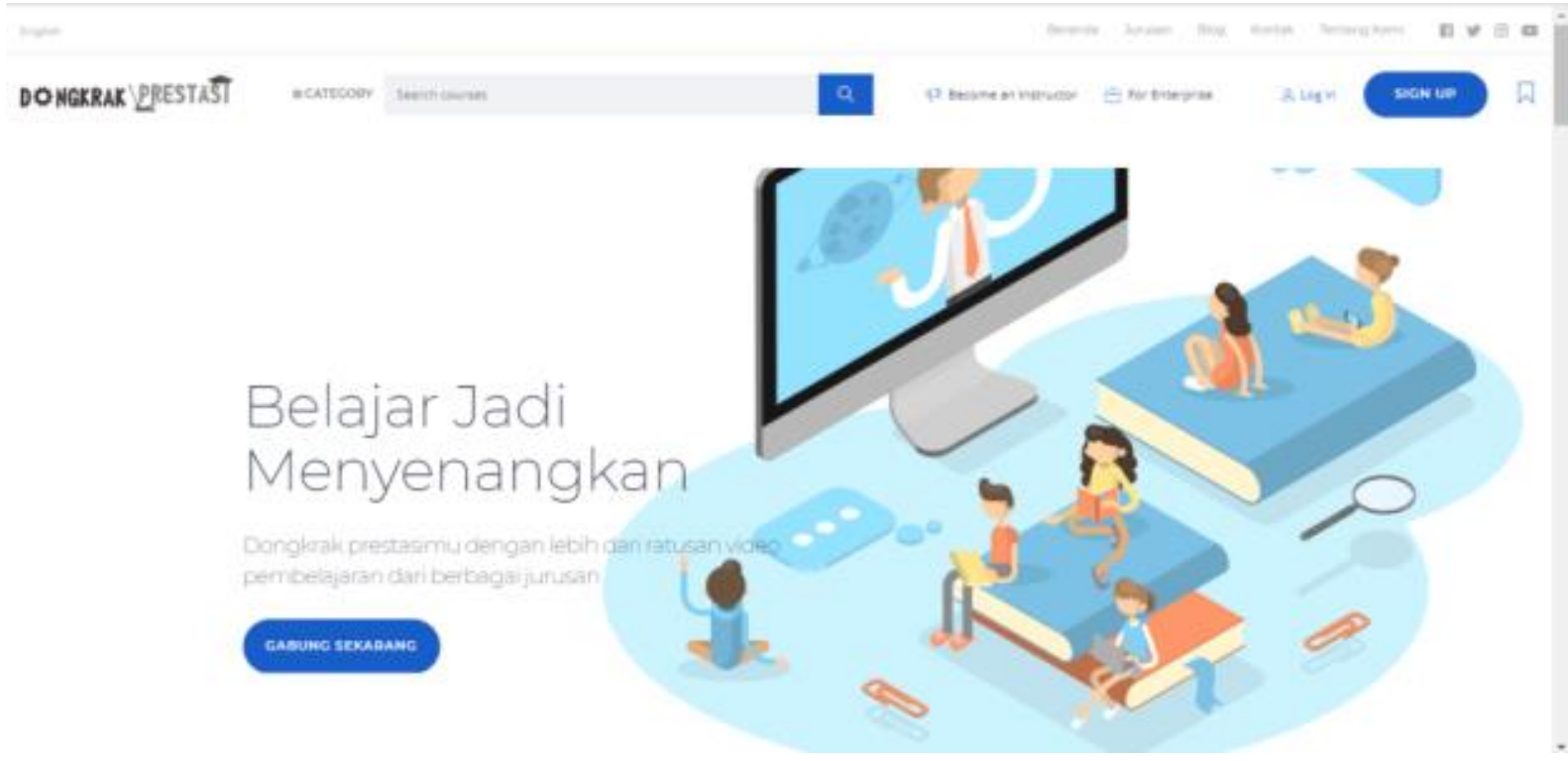

Gambar 3. Halaman Utama

(Sumber: Dokumen Pribadi)

Halaman utama merupakan tampilan yang muncul pertama kali ketika membuka website ini. Halaman ini menampilkan sebagian besar menu yang mengarah pada setiap fitur-fitur yang tersedia. Pada halaman ini pengguna dapat melihat berbagai macam materi pembelajaran berdasarkan jurusan dan kompetensi keahlian. Pada halaman ini juga pengguna dapat mendaftar sebagai member supaya dapat menggunakan fitur-fitur yang tersedia. Halaman utama ini bertujuan agar pengguna dapat memahami terlebih dahulu mengenai situs dongkrak prestasi beserta tujuannya sebelum digunakan.

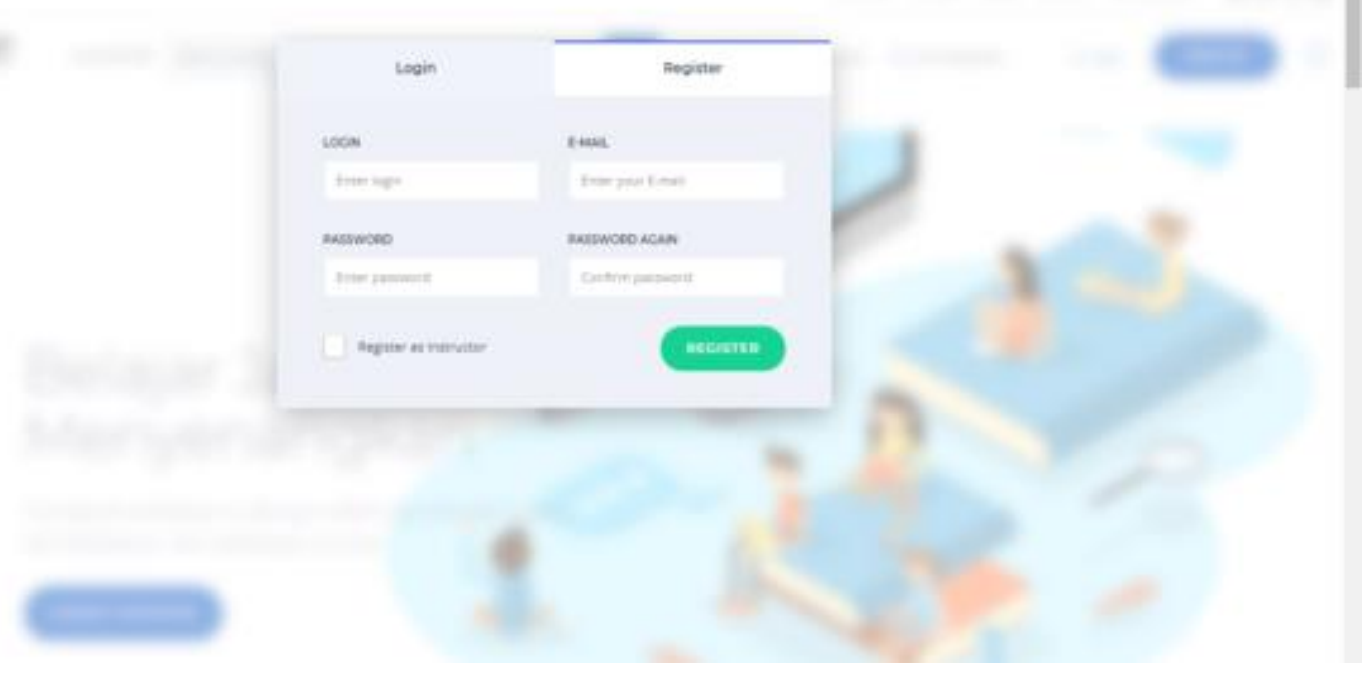

Gambar 4. Halaman Registrasi

(Sumber: Dokumen Pribadi) 
Fitur utama pada website ini dapat diakses oleh pengunjung apabila sudah mempunyai akun. Untuk mendapatkan akun tersebut, pengguna/siswa wajib mendaftar pada halaman registrasi. Halaman registrasi dapat diakses dengan menekan tombol "sign up" yang terdapat di menu. Pengunjung hanya perlu mengisi kolom yang tersedia seperti nama lengkap, username, email, dan password.

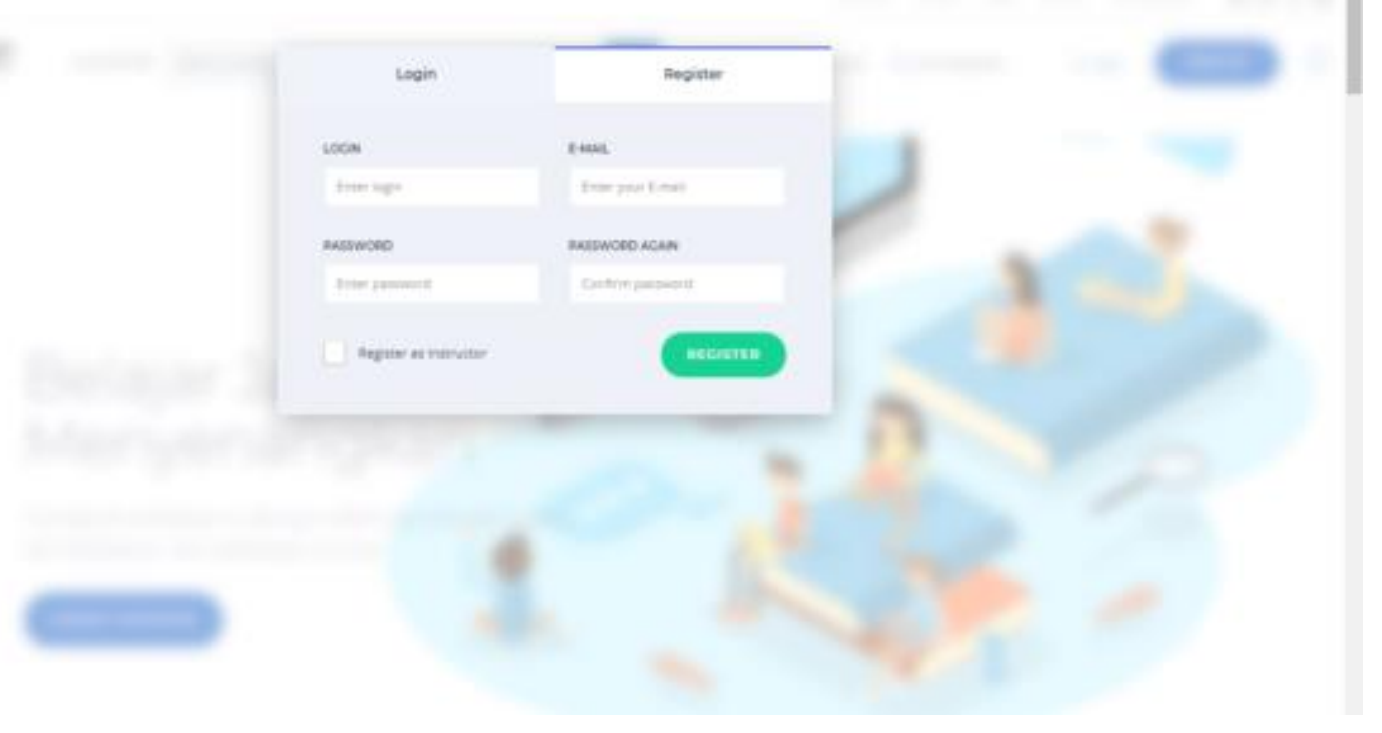

Gambar 5. Halaman Login

(Sumber: Dokumen Pribadi)

Setelah proses verifikasi adalah login ke member area. Pengguna harus memasukkan username dan password yang telah dibuat ketika proses pendaftaran. Pada halaman login disediakan juga fitur "lost password" untuk mengantisipasi pengguna/siswa ketika lupa.
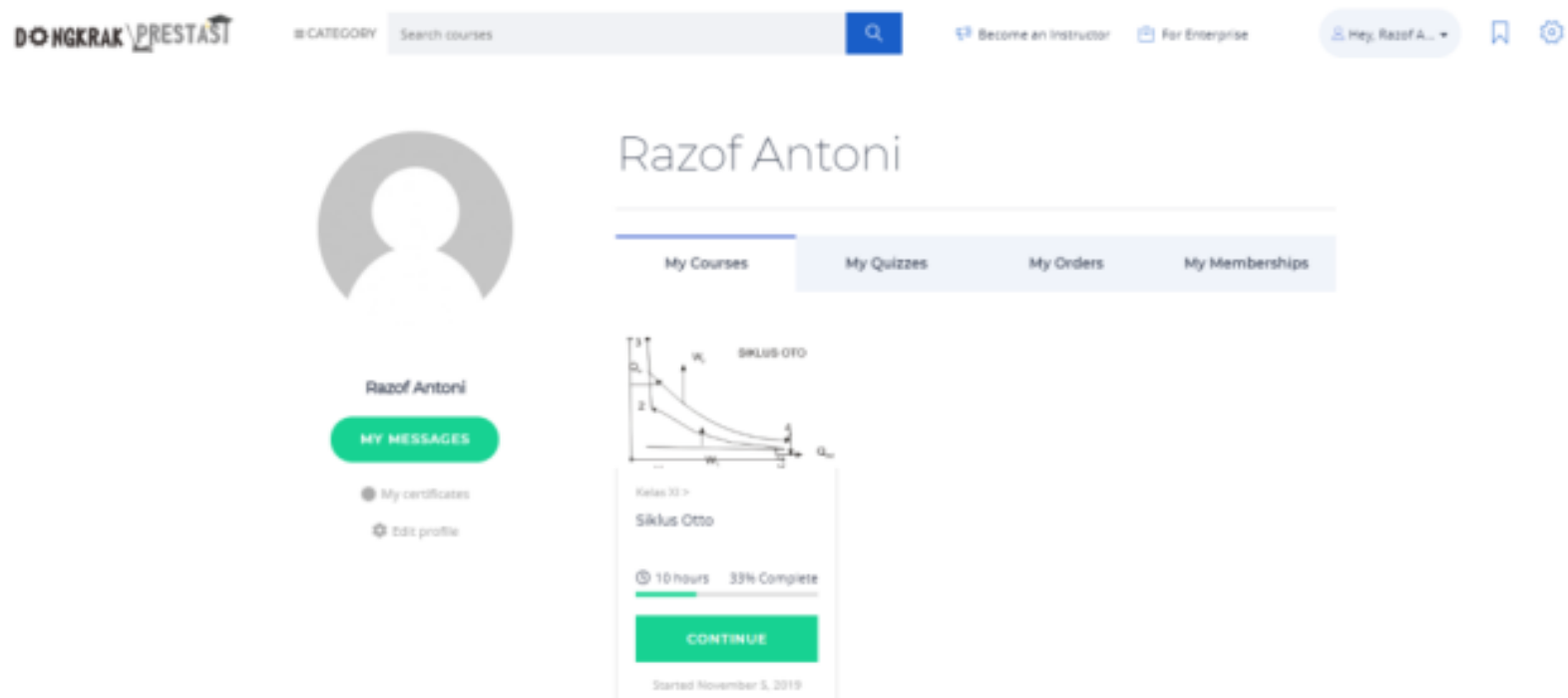

Gambar 6. Halaman Dashboard

(Sumber: Dokumen Pribadi)

Halaman dashboard merupakan halaman yang menampilkan riwayat pengguna/siswa selama mengakses website ini. Pada halaman ini terdapat tab my courses yang menampilkan video 
pembelajaran apa saja yang pernah diakses oleh user. Pada tab my quizzes menampilkan riwayat simulasi ujian yang pernah user kerjakan. Pengguna juga dapat mengedit biodata dengan menekan tombol edit profile.

DONGKrak DRESTAST
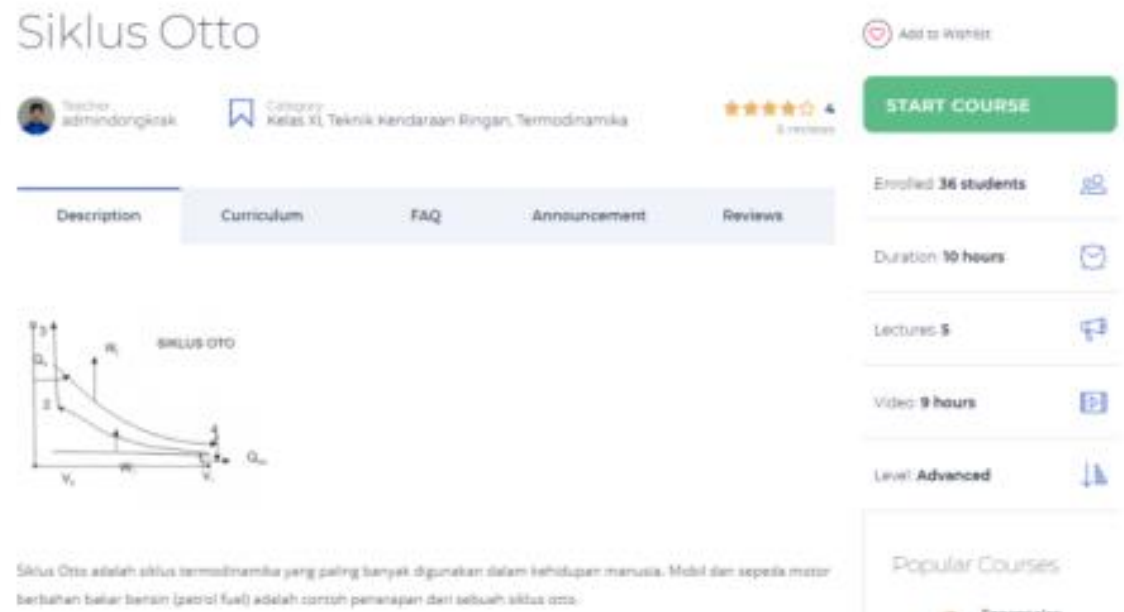

Gambar 7. Halaman Introduction Video Pembelajaran (Sumber: Dokumen Pribadi)

Sebelum pengguna mengakses video pembelajaran, terlebih dahulu akan ditampilkan halaman introduction. Pada halaman ini akan dijelaskan pendahuluan mengenai materi yang akan dipelajari. Di samping kanan deskripsi, terdapat informasi mengenai video pembelajaran seperti durasi video. Untuk memutar video yang dipilih, pengguna harus menekan tombol "start course".

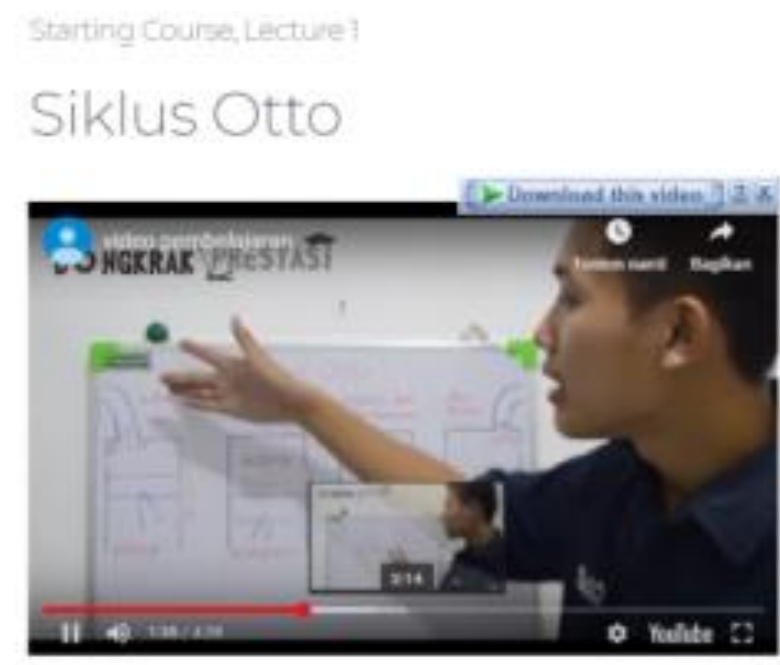

O. сомpurts

Gambar 8. Halaman Video Pembelajaran

(Sumber: Dokumen Pribadi) 
Fitur utama dari situs ini yaitu pembelajaran melalui video. Guru atau tutor akan menjelaskan materi sesuai dengan bidangnya masing masing. Pengguna bebas mengakses video-video pada jenjang SMK dari mulai kelas 1 sampai dengan kelas 3 sesuai kebutuhan mereka. Video dapat diputar baik melaui pc maupun smartphone. Pengguna dapat mengatur resolusi video sesuai dengan kebutuhan. Selain itu, video juga dapat diperbesar dengan memilih zoom sehingga video dapat memenuhi layar. Setelah menonton video, pengguna diharuskan menekan tombol "complete" agar sistem mendeteksi bahwa pengguna telah menyelesaikan video pembelajaran.

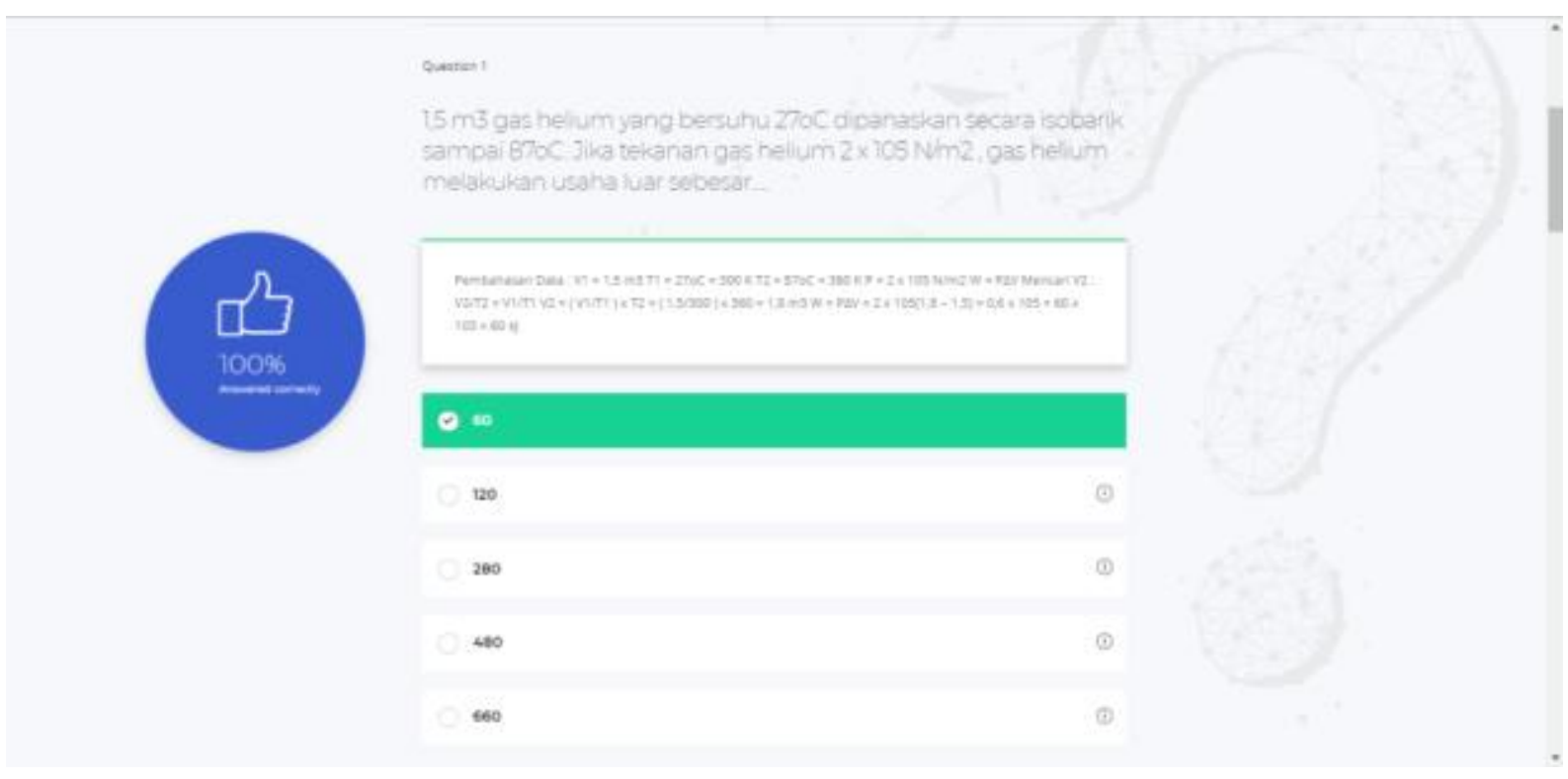

Gambar 9. Simulasi Ujian

(Sumber: Dokumen Pribadi)

Setelah pengguna menonton video pembelajaran, mereka akan dihadapkan dengan fitur simulasi ujian. Fitur ujian ini memungkinkan pengguna dapat mengevaluasi pemahaman mengenai materi yang telah dipelajari. Soal-soal ini disusun sesuai dengan kurikulum jenjang SMK yang pada umumnya digunakan sekolah-sekolah di Indonesia. Dengan latihan soal ini, diharapkan membantu pengguna mempertajam pengetahuan terhadap materi.

E

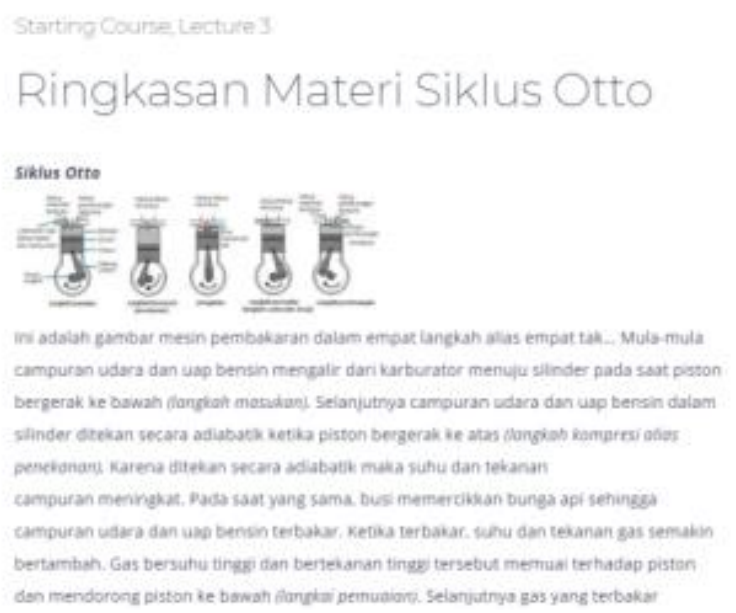

Gambar 10. Halaman Ringkasan Materi (Sumber: Dokumen Pribadi) 
Fitur ringkasan materi didapatkan setelah pengguna menyelesaikan simulasi ujian. Ringkasan materi ini dibuat berdasarkan materi pada video yang diputar. Fitur ini dihadirkan sebagai catatan apabila siswa ingin mengingat kembali materi yang telah dipelajari tanpa membuka video terlebih dahulu. Selain itu, siswa juga dapat mengetahui inti dari pembahasan pada video.

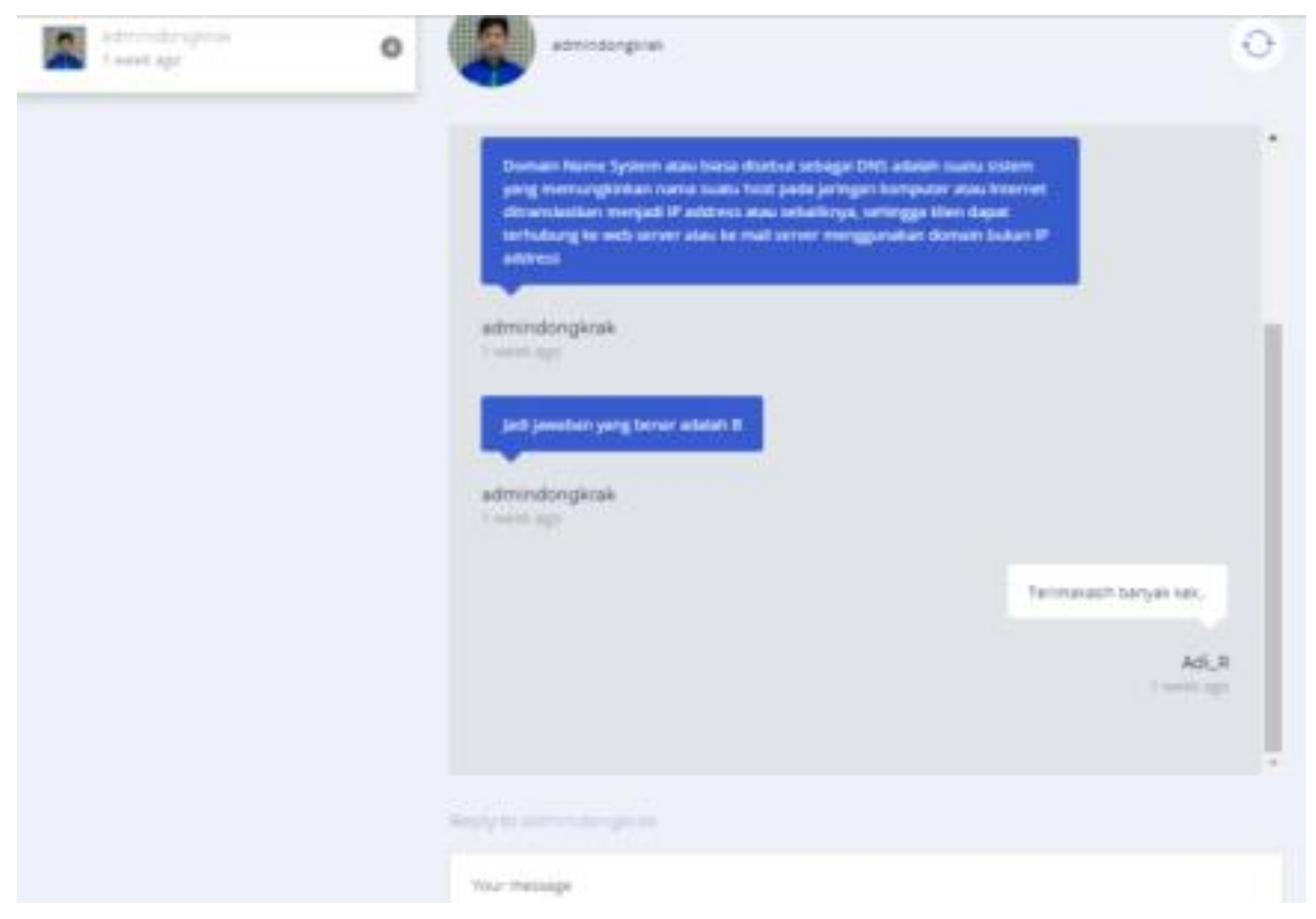

Gambar 11. Halaman Konsultasi

(Sumber: Dokumen Pribadi)

Fitur konsultasi dapat digunakan siswa untuk bertanya kepada administrator apabila membutuhkan penjelasan lebih lanjut mengenai materi yang telah dipelajari. Selain itu, siswa juga dapat bertanya tentang soal pekerjaan rumah yang dirasa sulit.

\section{Hasil Pengujian}

Pengujian dilakukan menggunakan blackbox testing oleh penulis dengan menguji fitur-fitur yang telah dibuat. Pengujian dilakukan menggunakan blackbox testing oleh stake holder yang terkait dengan aplikasi ini yaitu satu orang administrator, satu orang tutor, dan satu orang siswa/lulusan SMK.

Berdasarkan hasil pengujian dari 3 penguji yang mengisi angket menyatakan bahwa aplikasi pembelajaran ini sudah berjalan dengan hasil pengujian user interface $98 \%$, fungsi dasar sistem $100 \%$, dan validasi $100 \%$. Kesimpulannya aplikasi ini berjalan dengan sangat baik. 


\section{KESIMPULAN}

Dongkrak Prestasi merupakan aplikasi belajar online berbasis learning management system yang memungkinkan memungkinkan siswa dapat melakukan pembelajaran melalui video yang disampaikan oleh tutor. Masalah yang diangkat dalam penulisan penelitian ini adalah Bagaimana rancang bangun aplikasi belajar online berbasis web sebagai optimalisasi pembelajaran untuk siswa SMK. Metode pengembangan sistem yang digunakan adalah metode waterfall yang tahapannya terdiri atas requirement gathering, perencanaan, pengkodean, dan pengujian . Hasil dari pengembangan sistem ini adalah terciptanya sebuah aplikasi belajar omline berbasis web untuk siswa SMK dengan fitur video pembelajaran, simulasi ujian, ringkasan materi, konsultasi tutor, manajemen materi, dan manajemen tutor. Tahapan pembuatan aplikasi dimulai dari identifikasi masalah, pembuatan desain, pembuatan basis data dengan phpMyAdmin, pembuatan tampilan antarmuka, dan pembuatan logical business menggunakan PHP. Setelah dilakukan pengujian dengan metode blackbox testing, aplikasi belajar ini sudah bisa digunakan fungsi- fungsinya dan dikategorikan sangat baik.

\section{REFERENSI}

Ade Riyantika Dewi, R. I. (2015). Aplikasi Multimedia sebagai Media Pembelajaran Ilmu Pengetahuan Sosial Materi Budaya di Indonesia. Jurnal Teknologi dan Sistem Komputer, 3(4), 471-450.

Agung, G. (2000). Membuat Homepage Interaktif Dengan CGI/Perl. Jakarta: PT Elex Media Koputindo.

Anonim. (2019, Februari 12). Pertolongan Pertama Pada Kecelakaan, Apa yang Harus Dilakukan? Retrieved Juli 12, 2019, from Medi-Call: https://medi-call.id/blog/pertolongan-pertama-padakecelakaan/

Chusna, P. A. (2017). Pengaruh Media Gadget Pada Perkembangan. Dinamika Penelitian: Media Komunikasi Sosial Keagamaan, 315-329.

Febri Ramadhan, M. R. (2016). Perancangan Sistem Informasi Pembelajaran Online Berbasis Web Di Rumah Belajar Line-LCC. Jurnal Sistem Informasi Universitas Komputer Indonesia, 1-7.

Kurniawan, F., Saraswati, R., \& Fransiscus, G. (2018). Pengembangan Aplikasi Pencari Fasilitator KIR (Kelompok Ilmiah Remaja) Kelompok Peneliti Muda Universitas Negeri Jakarta (KPM UNJ) Berbasis Web. Risenologi : Jurnal Sains, Teknologi, Sosial, Pendidikan, Dan Bahasa, 3(2), 64-70.

Mulyadi. (2010). Diagnosis Kesulitan Belajar dan Bimbingan terhadap Kesulitan Belajar Khusus. Jakarta: Nuha Litera.

Nugrahanto, P. (2018, Januari 9). Tantangan dan Peluang Startup Pendidikan di Indonesia pada Tahun 2018. Retrieved September 16, 2019, from Universitas Al-Azhar Indonesia: https://entrepreneur.uai.ac.id/tantangan-dan-peluang-startup-pendidikan-di-indonesia-pada-tahun2018/

Perdani, A. (2013). Pengaruh Metode Snowball Throwing Dan Pemberian Tugas Terhadap Motivasi Belajar. Bandung: Universitas Pendidikan Indonesia.

Pressman, R. S. (2002). Rekayasa Perangkat Lunak . Yogyakarta: ANDI.

Riyanto. (2010). Sistem Informasi Penjualan Dengan PHP Dan MySQL. Yogyakarta: Gava Media.

Rudianto, A. (2011). Pemrograman Web Dinamis menggunakan PHP dan MySQL. Yogyakarta: CV ANDI .

S, E. P. (2009). Evaluasi Program Pembelajaran. Yogyakarta: Pustaka Pelajar. 
Saurina, N. (2018). Aplikasi Pembelajaran IPA Untuk Siswa Homeschooling Pena. INTEGER: Journal of Information Technology, 3(1), 45-56.

Sumardani, D, Midaraeni, I., Sumardani, NI. 2019. Virtual Reality Sebagai Media Pembelajaran Relativitas Khusus Berbasis Google Cardboard pada Smartphone Android. Prosiding Seminar Nasional Pendidikan KALUNI 2. 